Narrative Reviews

\title{
Placental Mesenchymal Dysplasia: Chronological Observation of Placental Images during Gestation and Review of the Literature
}

Satoshi Ohira ${ }^{\mathrm{a}}$, Nao Ookubo ${ }^{\mathrm{a}}$, Kyoko Tanaka ${ }^{\mathrm{a}}$, Akiko Takatsu ${ }^{\mathrm{a}}$, Hisanori Kobara ${ }^{\mathrm{a}}$, Norihiko Kikuchi $^{\text {a }}$, Ayumi Ohya ${ }^{\text {b }}$, Makoto Kanai ${ }^{\text {a }}$, Tanri Shiozawa ${ }^{\text {a }}$

Department of abstetrics and Gynecology, ${ }^{b}$ Radiology, Shinshu University School of Medicine, Matsumoto, Japan

3-1-1 Asahi, Matsumoto 390-8621, Japan

Running title: Placental Mesenchymal Dysplasia

Address correspondence and reprint requests to:

Tanri Shiozawa, M.D. Department of Obstetrics and Gynecology, Shinshu University

School of Medicine, 3-1-1 Asahi, Matsumoto 390-8621, Japan

FAX: +81-263-34-0944; TEL: +81-263-37-2719

e-mail: tanri@shinshu-u.ac.jp 
Key words: Placental mesenchymal dysplasia, Ultrasound, Magnetic resonance imaging

\begin{abstract}
Placental mesenchymal dysplasia (PMD) is characterized by multiple hypoechoic vesicles, which are similar to molar changes in the placenta; however, the process of such morphological changes of PMD during pregnancy has not been fully understood. We performed a review of all PMD cases published in English, identified 49 articles including 110 cases. With regard to the gestational age at which the multi-cystic pattern was seen, approximately $70 \%$ of cases were diagnosed at 13-20 weeks of gestation. Another characteristic feature of PMD is varicose dilation of fetal chorionic vessels. Ninety $\%$ of cases were diagnosed as placenta with dilated fetal chorionic vessels in the third-trimester. We also report a case of PMD which was found at 10 weeks of gestation according to ultrasonic molar patterns. Serial observations of the placenta using ultrasound and magnetic resonance imaging revealed that multi-cystic lesions became smaller after 23 weeks. In contrast, dilated placental vessels on the fetal side became apparent at 38 weeks. The present review highlights that PMD’s placental vesicular lesions may precede dilation of fetal chorionic vessels during pregnancy. We also indicated that the potential of a gradual reduction in size of PMD's placental vesicular lesions by serial study of placental images.
\end{abstract}




\section{Introduction}

Placental mesenchymal dysplasia (PMD) is a rare condition of pregnancy that presents as multiple hypoechoic vesicles, which are similar to molar changes in the placenta. It is estimated to occur in $0.02 \%$ of pregnancies [1]. These cases are often misdiagnosed as partial mole or twin pregnancy with complete mole and coexistent fetus. Most cases of PMD show multi-cystic area in ultrasonography at 13 weeks or later of gestation [2]. Another characteristic feature of PMD is varicose dilation of fetal chorionic vessels. Although approximately one hundred cases of PMD have been reported, serial course of PMD’s placental appearance during pregnancy have not been elucidated. We review previously reported cases of PMD in relation to presented gestational age of multi-cystic pattern and dilated chorionic vessels of the placenta.

\section{Literature}

We performed a review of all PMD cases published in English between 1986 and April 2012. All studies were derived from Medline using the terms 'placental mesenchymal dysplasia' and references of articles. All articles without an abstract or with unavailable full text were excluded. We identified 49 articles including 110 cases of PMD [1-49].

\section{Clinical Case}

We recently observed a 32-year-old, primigravida woman who referred to our hospital at 12 weeks of gestation because of multi-cystic patterns in ultrasonography detected at 10 weeks of gestation. Ultrasound identified a large area of chorionic tissue consistent with a molar tissue pattern (Fig. 1); normal chorionic tissue was unclear. Fetal growth and amniotic fluid volume were normal. Partial mole or twin pregnancy with complete mole and coexistent fetus, or PMD was initially suspected. Serum human chorionic gonadotropin (hCG) was 241,270 mIU/mL at 12 weeks of gestation, and the titer gradually decreased. Amniocytes were collected at 17 weeks of gestation, and the 
karyotype was 46,XX. Because the fetal karyotype was normal diploid and serum hCG levels were not elevated as complete mole, PMD was finally suspected. Magnetic resonance imaging (MRI) at 17 weeks of gestation showed that the whole area of the placenta was occupied by small cysts 2-15 mm in diameter (Fig. 2a). After 23 weeks of gestation, serial ultrasonic evaluation revealed a gradual reduction of size in placental vesicular lesions (Fig. 3a, 3b). After 29 weeks of gestation, placental multi-cystic pattern was indistinct (Fig. $\underline{\text { 3c) }}$ ), but the placenta was thick in ultrasonography. MRI at 34 weeks of gestation showed almost normal appearance of the placental parenchyma (Fig. 2b). In ultrasonography, the fetus demonstrated reduced growth parameters from 34 weeks of gestation, and dilated superficial placental vessels were observed on the fetal side at 38 weeks of gestation (Fig. $\underline{4 a}$ ). Because non-reassuring fetal status including prolonged decelerations in fetal heart rate monitoring was observed at 39 weeks of gestation, cesarean section was performed. The newborn was a $1998 \mathrm{~g}$ female (<3 percentile) with Apgar scores of 8 and 9 at 1 min and 5 min, respectively. The placenta weighed $1200 \mathrm{~g}$. Fetal plate of the placenta showed aneurismal and varicose dilations of chorionic vessels (Fig. $\underline{4 \mathrm{~b}}$ ). Microscopically, stem villi contained some dilated vessels with thrombosis. Some terminal villi contained increased density of fibroblastic cells (Fig. 4c). Stem villi occasionally showed hydropic swelling with cistern formation. Abnormal trophoblastic proliferation and inclusion were not observed. These pathological findings were compatible with PMD. The patient's puerperal course was uneventful.

\section{Results}

PMD has a high incidence of fetal growth restriction and intrauterine fetal death, and is associated with Beckwith-Wiedemann syndrome (BWS), a condition characterized by macrosomia, visceromegaly, macroglossia, and omphalocele [18]. Of the 110 cases reviewed, 16 (14.5\%) were associated with BWS [2-10], 33 (30.0\%) had evidence of 
fetal growth restriction [4, 11-24, 41, 46, 48] as the current case, and 28 (25.5\%) ended

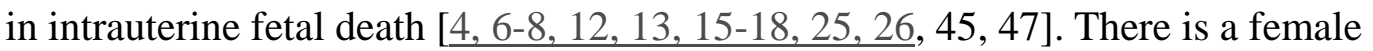
preponderance in cases of PMD; 78 females and 19 males of which presented the data of infants were reviewed.

Of the 110 cases reviewed, 44 cases of PMD showed multi-cystic placenta in antenatal ultrasound scan $[\underline{1-3,5,7,9-13,16,18-20, ~ 22, ~ 23, ~ 26-34, ~ 41-48] . ~ F i g u r e ~} \underline{5}$ represents the gestational age that the multi-cystic pattern was identified in 44 cases and the current case. Approximately $70 \%$ of cases were diagnosed as multi-cystic placenta at 13-20 weeks of gestation. Another characteristic feature of PMD is aneurismal and varicose dilation of fetal chorionic vessels. Of the 110 cases reviewed, 48 cases of PMD presented the data of dilation of fetal chorionic vessels [2, 3, 9, 11-15, 17, 18, 20-24, 26, 34-36, 40, 41, 44-48]. Figure $\underline{6}$ represents the gestational age when aneurismal and varicose dilation of chorionic vessels were identified in 48 cases and the current case. Ninety \% of cases were diagnosed as placenta with dilated fetal chorionic vessels in the third-trimester, and $55 \%$ of cases showed this feature after 36 weeks of gestation.

\section{Discussion}

PMD is a rare disorder. The increased propensity of PMD in BWS and female infants has led to speculation that genes important for the development of PMD may be related to the BWS complex (11p15.5) or the X chromosome [1] , but the genetic constituency and pathogenesis of PMD is unclear.

Prenatal differential diagnosis of PMD is partial mole or twin pregnancy with complete mole and coexistent fetus. It is important to distinguish PMD from molar pregnancy because it may avoid unnecessary termination of pregnancy, especially if prenatal ultrasonographic examination shows features suggestive of molar pregnancy in the presence of a normally appearing fetus. Fetal karyotype is an important initial factor in distinguishing PMD from partial mole. While partial mole is usually triploid, fetus 
with PMD is almost always diploid [23]. Although it is difficult to distinguish PMD from twin pregnancy with complete mole and coexistent fetus in terms of prenatal imaging of the placenta, serum hCG levels with PMD are reportedly lower than that of complete mole [23]; the peak of serum hCG levels with PMD may be up to 500,000 $\mathrm{mIU} / \mathrm{mL}$ as normal pregnancies.

Serial course of PMD’s placental image during pregnancy have not been elucidated. Our review showed approximately 70 \% of cases was diagnosed as multi-cystic placenta at 13-20 weeks of gestation. Meanwhile, in the several cases, the multi-cystic pattern in ultrasonography was detected prior to 13 weeks of gestation as the current case. Thus, the morphological changes in the villi appear to begin early during gestation. Our review also showed that no previous report of PMD had detected aneurismal and varicose dilation of fetal chorionic vessels prior to 25 weeks of gestation. These findings suggest that vascular malformation develops progressively after the late second-trimester. Macroscopic features of aneurismal and varicose dilation of fetal chorionic vessels may be secondary changes in circulatory disorders in PMD’s multicystic placenta.

Serial change of the size of PMD's vesicular lesions during pregnancy has not been also elucidated. Only two reports stated that sonographic evaluation of a case of PMD revealed a reduction in size of placental vesicular lesions as the pregnancy advanced $[\underline{23}, 45]$. Our case also revealed a gradual reduction in size of placental vesicular lesions by serial study of placental images including ultrasound and MRI; therefore, PMD’s placental vesicular lesions may have the potential of a gradual reduction in size. Although ultrasonography is suitable for observation of the placenta, MRI is more fitting to understand whole intrauterine structures using 3-dimensional observations. Moreover, there have been no reports of PMD’s imaging using MRI. Therefore, we consider that the use of MRI in combination with ultrasonography can be a potent strategy in chronological observation of PMD during pregnancy. In the current 
case, we could certainly see that vesicular lesions occupied not partial but whole area of the placenta due to the wider field of view and excellent tissue contrast of MRI.

With regard to the pathogenesis of PMD, Heazell et al. [1] described that cells lining the cistern in PMD were labeled with D2-40, an established lymphatic marker immunohistochemically. Therefore, vesicular lesions in PMD’s placenta may be caused by abnormal lymphangiogenesis. Although the reason for the gradual reduction in size of placental vesicular lesions is unclear, we speculate that lymph vessel-like structures in PMD’s placenta may be reduced rather than increased.

In summary, the present review highlights that PMD’s placental vesicular lesions may precede dilation of fetal chorionic vessels during pregnancy. We also indicated that the potential of a gradual reduction in size of PMD's placental vesicular lesions by serial study of placental images including ultrasound and MRI. Further studies are needed to clarify the etiology and pathogenesis of PMD.

\section{References}

1. Heazell AEP, Sahasrabudhe N, Grossmith AK, Martindale EA, Bhatia K: A case of intrauterine growth restriction in association with placental mesenchymal dysplasia with abnormal placental lymphatic development. Placenta 2009;30:654-657.

2. Chan YF, Sampson A: Placental mesenchymal dysplasia: a report of four cases with differentiation from partial hydatidiform mole. Aust N Z J Obstet Gynaecol 2003;43:475-479.

3. Jauniaux E, Nicolaides KH, Hustin J: Perinatal features associated with placental mesenchymal dysplasia. Placenta 1997;18:701-706.

4. Arizawa M, Nakayama M: Suspected involvement of the X chromosome in placental mesenchymal dysplasia. Congenit Anom (Kyoto) 2002;42:309-317.

5. Hillstrom MM, Brown DL, Wilkins-Haug L, Genest DR: Sonographic appearance of placental villous hydrops associated with Beckwith-Wiedemann syndrome. J 
Ultrasound Med 1995;14:61-64.

6. Lage JM: Placentomegaly with massive hydrops of placental stem villi, diploid DNA content, and fetal omphaloceles: possible association with Beckwith-Wiedemann syndrome. Hum Pathol 1991;22:591-597.

7. McCowan LM, Becroft DM: Beckwith-Wiedemann syndrome, placental abnormalities, and gestational proteinuric hypertension. Obstet Gynecol 1994;83:813-817.

8. Paradinas FJ, Sebire NJ, Fisher RA, Rees HC, Foskett M, Seckl MJ, Newlands ES: Pseudo-partial moles: placental stem vessel hydrops and the association with Beckwith-Wiedemann syndrome and complete moles. Histopathology 2001;39:447-454.

9. Takayama M, Soma H, Yaguchi S, Funayama H, Fujiwara K, Irie H, Yamane S: Abnormally large placenta associated with Beckwith-Wiedemann syndrome. Gynecol Obstet Invest 1986;22:165-168.

10. H’mida D, Gribaa M, Yacoubi T, Chaieb A, Adala L, Elghezal H, Saad A: Placental mesenchymal dysplasia with Beckwith-Wiedemann syndrome fetus in the context of biparental and androgenic cell lines. Placenta 2008;29:454-460.

11. Chen CP, Chern SR, Wang TY, Huang ZD, Huang MC, Chuang CY: Pregnancy with concomitant chorangioma and placental vascular malformation with mesenchymal hyperplasia. Human Reprod 1997;12:2533-2556.

12. Cohen MC, Roper EC, Sebire NJ, Stanek J, Anumba DOC: Placental mesenchymal dysplasia associated with fetal aneuploidy. Prenat Diag 2005;25:187-192.

13. Kaiser-Rogers KA, McFadden DE, Livasy CA, Dansereau J, Jiang R, Knops JF, Lefebvre L, Rao KW, Robinson WP: Androgenetic/biparental mosaicism causes placental mesenchymal dysplasia. J Med Genet 2006;43:187-192.

14. Lee GK, Chi JG, Cha KS: An unusual venous anomaly of the placenta. Am J Clin Pathol 1991;95:48-51. 
15. Ohyama M, Kojyo T, Gotoda H, Sato T, Ijiri R, Tanaka Y: Mesenchymal dysplasia of the placenta. Pathol Int 2000;50:759-764.

16. Pridmore BR, Khong TY, Wells WA: Ultrasound placental cysts associated with massive placental stem villous hydrops, diploid DNA content, and exomphalos. Am J Perinatol 1994;11:14-18.

17. Sander CM: Angiomatous malformation of placental chronic stem vessels and pseudo-partial molar placentas: report of five cases. Pediatr Pathol 1993;13:621-633.

18. Pham T, Steele J, Stayboldt C, Chan L, Benirschke K: Placental mesenchymal dysplasia is associated with high rates of intrauterine growth restriction and fetal demise: a report of 11 new cases and review of the literature. Am J Clin Pathol 2006;126:67-78.

19. Jalil SSA, Mahran MA, Sule M: Placental mesenchymal dysplasia: can it be predicted prenatally? a case report. Prenat Diagn 2009;29:713-714.

20. Vaisbuch E, Romero R, Kusanovic JP, Erez O, Mazaki-Tovi S, Gotsch F, Kim CJ, Kim JS, Yeo L, Hassan SS: Three dimentional sonographic imaging of placental mesenchymal dysplasia and its differential diagnosis. J Ultrasound Med 2009;28:359-368.

21. Aviram R, Kidron D, Silverstein S, Lerer I, Abeliovich D, Tepper R, Dolfin Z, Markovitch O, Arnon S: Placental mesenchymal dysplasia associated with transient neonatal diabetes mellitus and paternal UPD6. Placenta 2008;29:646-649.

22. Robinson WP, Lauzon JL, Innes AM, Lim K, Arsovska S, McFadden DE: Origin and outcome of pregnancies affected by androgenetic/biparental chimerism. Hum Reprod 2007;22:1114-1122.

23. Kinoshita T, Fukaya S, Yasuda Y, Itoh M: Placental mesenchymal dysplasia. J Obstet Gynaecol Res 2007;33:83-86.

24. Reed RC, Beischel L, Schoof J, Johnson J, Raff ML, Kapur RP: Androgenic/biparental mosaicism in an infant with hepatic mesenchymal hamartoma 
and placental mesenchymal dysplasia. Pediatr Dev Pathol 2008;11:377-383.

25. Robinson WP, Slee J, Smith N, Murch A, Watson SK, Lam WL, McFadden DE: Placental mesenchymal dysplasia associated with fetal overgrowth and mosaic deletion of the maternal copy of 11p15.5. Am J Med Genet Part A 2007;143A:1752-1759.

26. Tortoledo M, Galindo A, Ibarrola C: Placental mesenchymal dysplasia associated with hepatic and pulmonary hamartoma. Fetal Pediatr Pathol 2010;29:261-270.

27. Feinberg RF, Lockwood CJ, Salafia C, Hobbins JC: Sonographic diagnosis of a pregnancy with a diffuse hydatidiform mole and coexistent $46, \mathrm{XX}$ fetus: a case report. Obstet Gynaecol 1988;72:485-488.

28. Furuhashi M, Oda H, Nakashima T: Hydrops of placental stem villi complicated with fetal congenital adrenal hyperplasia. Arch Gynecol Obstet 2000;264:101-104.

29. Müngen E, Dundar Ö, Muhcu M, Haholu A, Tunca Y: Placental mesenchymal dysplasia associated with trisomy 13: sonographic findings. J Clin Ultrasound 2008;36:454-456.

30. Ang DC, Urrego PAR, Prasad V: Placental mesenchymal dysplasia: a potential misdiagnosed entity. Arch Gynecol Obstet 2009;279:937-939.

31. Schuetzle MN, Uphoff TS, Hatten BA, Dawson DB: Utility of microsatellite analysis in evaluation of pregnancies with placental mesenchymal dysplasia. Prenat Diagn 2007;27:1238-1244.

32. Wilson M, Peters G, Bennetts B, McGillivray G, Wu ZH, Poon C, Algar E: The clinical phenotype of mosaicism for genome-wide paternal uniparental disomy: two new reports. Am J Med Genet Part A 2008;146A:137-148.

33. Morales C, Soler A, Badenas C, Rodríguez-Revenga L, Nadal A, Martínez JM, Mademont-Soler I, Borrell A, Mirà M, Sánchez A: Reproductive consequences of genome-wide paternal uniparental disomy mosaicism: description of two cases with different mechanisms of origin and pregnancy outcomes. Fertil Steril 
2009;92:393.e5-e9.

34. Kitano Y, Ruchelli E, Weiner S, Adzick NS: Hepatic mesenchymal hamartoma associated with mesenchymal stem villous hyperplasia of the placenta. Fetal Diagn Ther 2000;15:134-138.

35. Moscoso G, Jauniaux E, Hustin J: Placental vascular anomaly with diffuse mesenchymal stem villous hyperplasia: a new clinic-pathological entity? Path Res Pract 1991;187:324-328.

36. Højberg KE, Aagaard J, Henriques U, Sunde L: Placental vascular malformation with mesenchymal hyperplasia and a localized chorioangioma: a rarity simulating partial mole. Path Res Pract 1994;190:808-813.

37. Matsui H, Iitsuka Y, Yamazawa K, Tanaka N, Mitsuhashi A, Seki K, Sekiya S: Placental mesenchymal dysplasia initially diagnosed as partial mole. Pathol Int 2003;53:810-813.

38. Gibson BR, Muir-Padilla J, Champeaux A, Suarez ES: Mesenchymal dysplasia of the placenta. Placenta 2004;25:671-672.

39. Hoffner L, Dunn J, Esposito N, Macpherson T, Surti U: p57KIP2 immunostaining and molecular cytogenetics: combined approach aids in diagnosis of morphologically challenging cases with molar phenotype and in detecting androgenetic cell lines in mosaic/chimeric conceptions. Hum Pathol 2008;39:63-72.

40. Francis B, Hallam L, Kecskes Z, Ellwood D, Croaker D, Kent A: Placental mesenchymal dysplasia associated with hepatic mesenchymal hamartoma in the newborn. Pediatr Dev Pathol 2007;10:50-54.

41. Starikov R, Goldman R, Dizon DS, Kostadinov S, Carr S: Placental mesenchymal dysplasia presenting as a twin gestation with complete molar pregnancy. Obstet Gynecol 2011;118:445-449.

42. Ruhland B, Schröer A, Gembruch U, Noack F, Weichert J: Prenatal imaging and postnatal pathologic work-up in a case of fetal hepatic hamartoma and placental 
mesenchymal dysplasia. Ultrasound Obstet Gynecol 2011;38:360-365.

43. Mack-Detlefsen B, Bormers TM, Groneck P, Bald R: Multiple hepatic mesenchymal hamartomas in a premature associated with placental mesenchymal dysplasia. $\mathrm{J}$ Pediatr Surg 2011;46:E23-E25.

44. Woo GW, Rocha FG, Gaspar-Oishi M, Bartholomew ML, Thompson KS: Placental mesenchymal dysplasia. Am J Obstet Gynecol 2011;205:e3-e5.

45. Umazume T, Kataoka S, Kamamuta K, Tanuma F, Sumie A, Shirogane T, Kudou T, Ikeda H: Placental mesenchymal dysplasia, a case of intrauterine sudden death of fetus with rupture of cirsoid periumbilical chorionic vessels. Diagn Pathol 2011;6:38.

46. Gizzo S, Gangi SD, Patrelli TS, Saccardi C, D’Antona D, Nardelli GB: Placental mesenchymal dysplasia: can early diagnosis ensure a good materno-foetal outcome? A case report. Arch Gynecol Obstet DOI: 10.1007/s00404-012-2232-7.

47. Zeng X, Chen MF, Bureau Y-A, Brown R: Placental mesenchymal dysplasia and an estimation of the population incidence. Acta Obstet Gynecol Scand 2012;91:DOI:10.1111/j.1600-0412.2012.01397.x.

48. Surti U, Hill LM, Dunn J, Prosen T, Hoffner L. Twin pregnancy with a chimeric androgenetic and biparental placenta in one twin displaying placental mesenchymal dysplasia phenotype. Prenat Diagn 2005;25:1048-1056.

49. Mulch AD, Stallings SP, Salafia CM. Elevated maternal serum alpha-fetoprotein, umbilical vein varix, and mesenchymal dysplasia: are they related? Prenat Diagn 2006;26:659-661. 


\section{Figure legends}

Figure 1. Ultrasonographic image at 12 weeks of gestation. The multi-cystic pattern existed within the parenchyma of chorionic tissue (surrounded by arrows).

Figure 2. T2-weighted sagittal images of magnetic resonance imaging (MRI). a: MRI at 17 weeks of gestation. Whole area of the placenta (surrounded by arrows) was occupied by small cysts $2-15 \mathrm{~mm}$ in diameter. $\mathbf{b}$ : MRI at 34 weeks of gestation. Almost normal appearance of the placental parenchyma was observed (arrows).

Figure $\underline{3}$. Serial study of placental ultrasonographic images. a: At 22 weeks of gestation b: At 26 weeks of gestation c: At 29 weeks of gestation. Serial ultrasonic evaluation revealed a gradual reduction in size of placental vesicular lesions. After 29 weeks of gestation, placental multi-cystic pattern was indistinct.

Figure $\underline{4}$. a: Ultrasonography at 38 weeks of gestation. Dilated superficial placental vessels were observed on the fetal side (arrow). b: Macroscopically, fetal plate of the placenta showed aneurismal and various dilations of chorionic vessels. c: Microscopically, stem villi contained some dilated vessels with thrombosis. Some terminal villi contained increased density of fibroblastic cells (arrows).

Figure 5. Presented gestational age of multi-cystic pattern in 44 cases and the current case

Figure 6. Presented gestational age of aneurismal and varicose dilation of chorionic vessels in 48 cases and the current case 


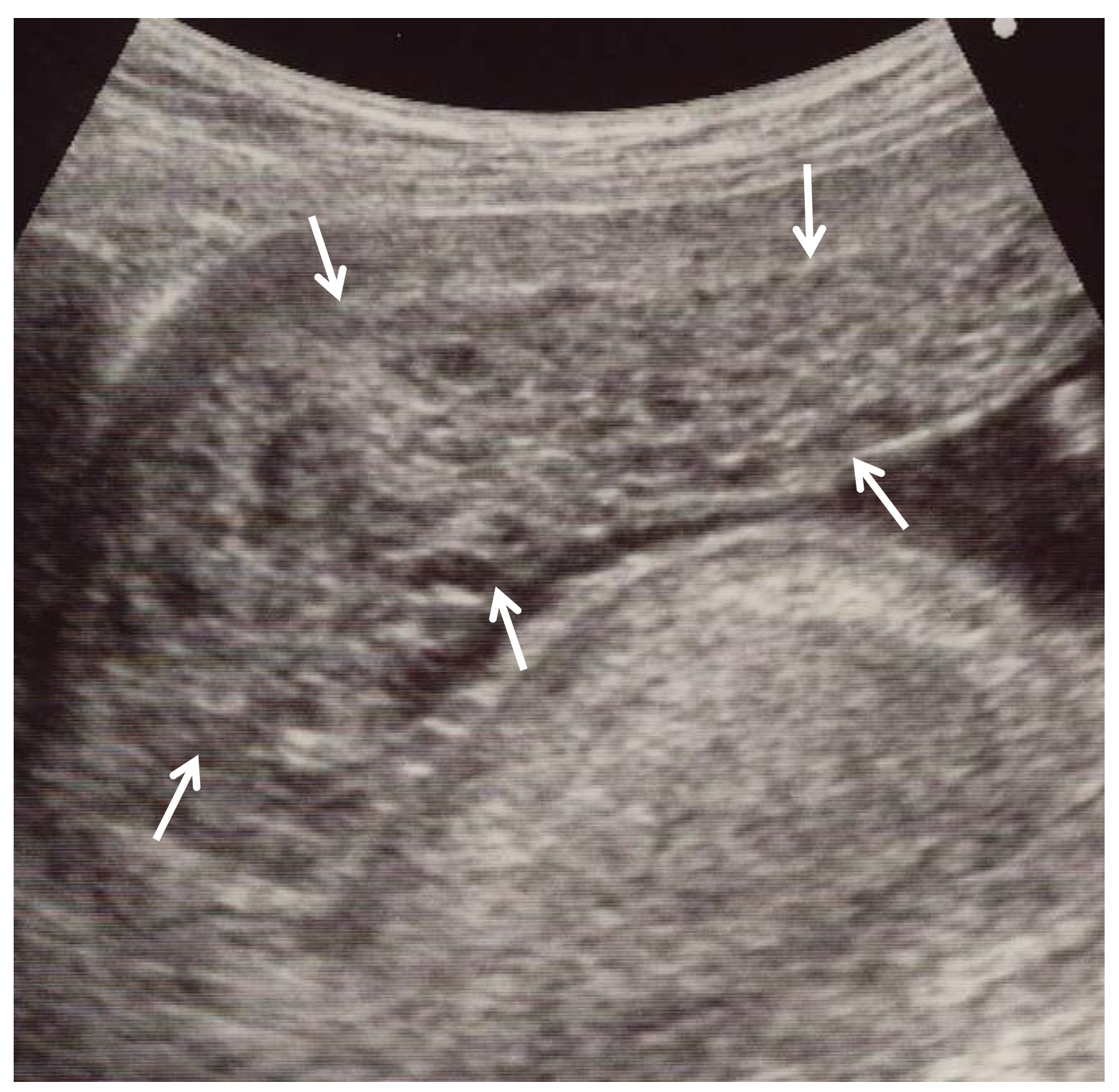

Figure 1 


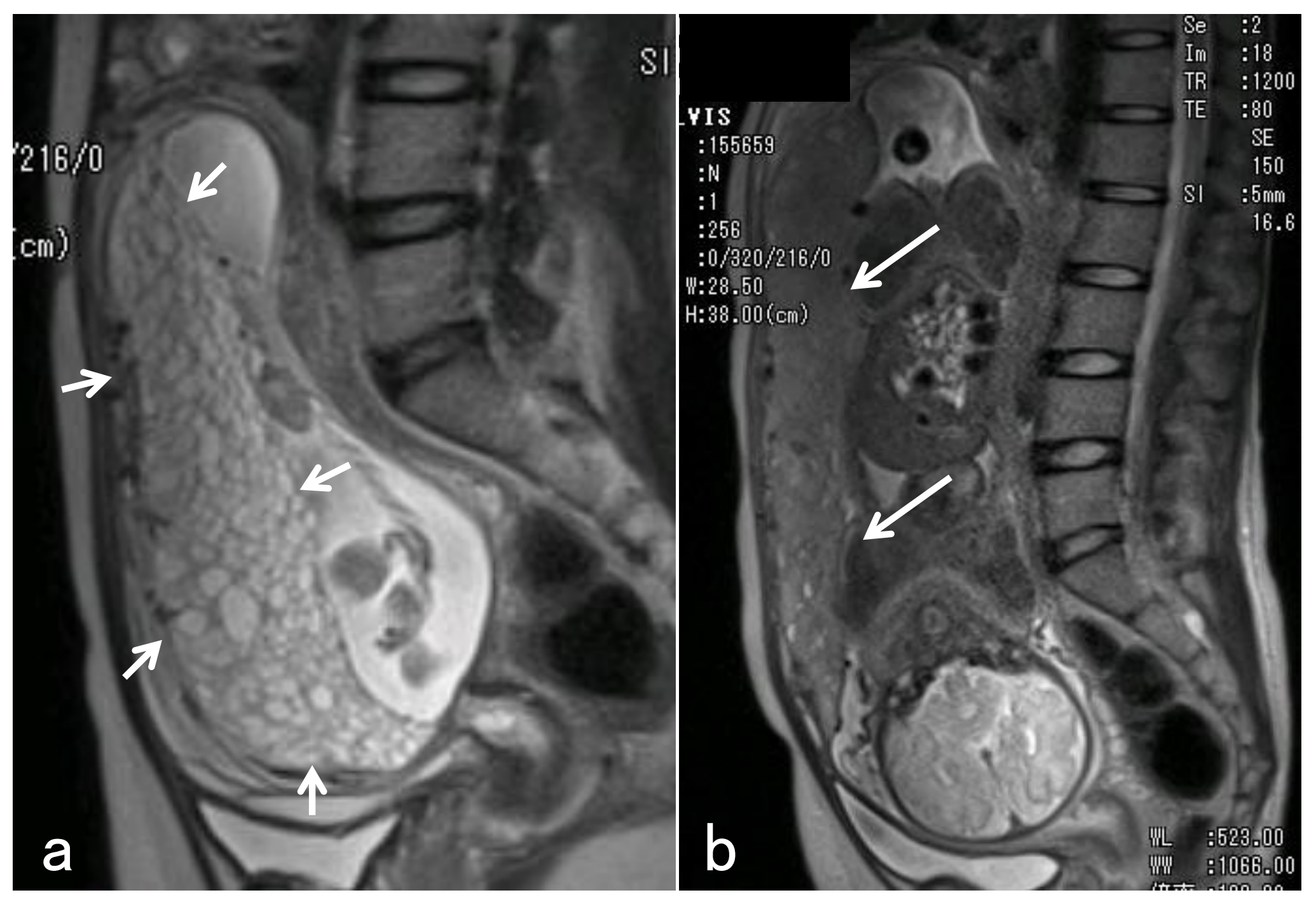

Figure 2 

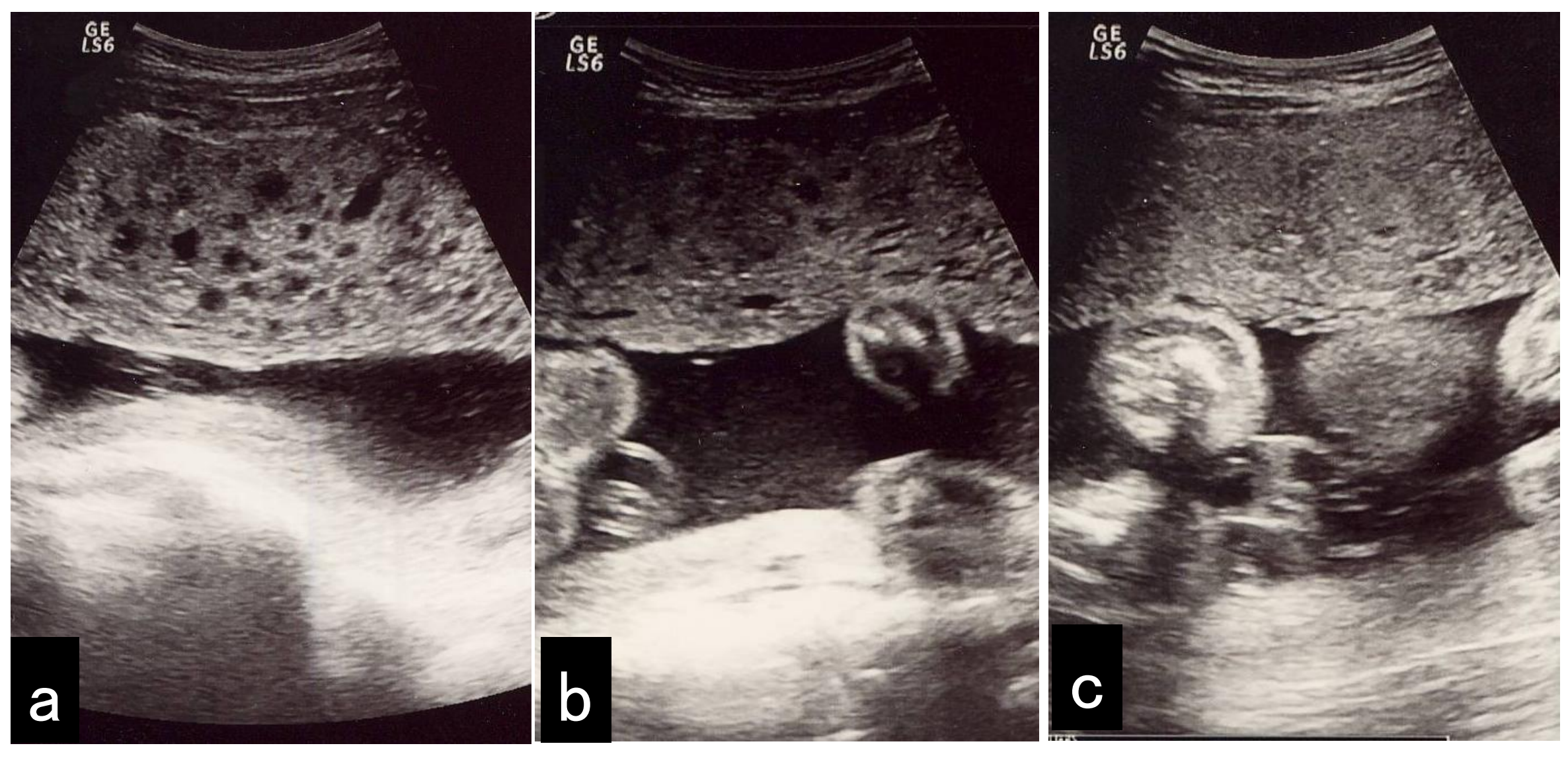

Figure 3 

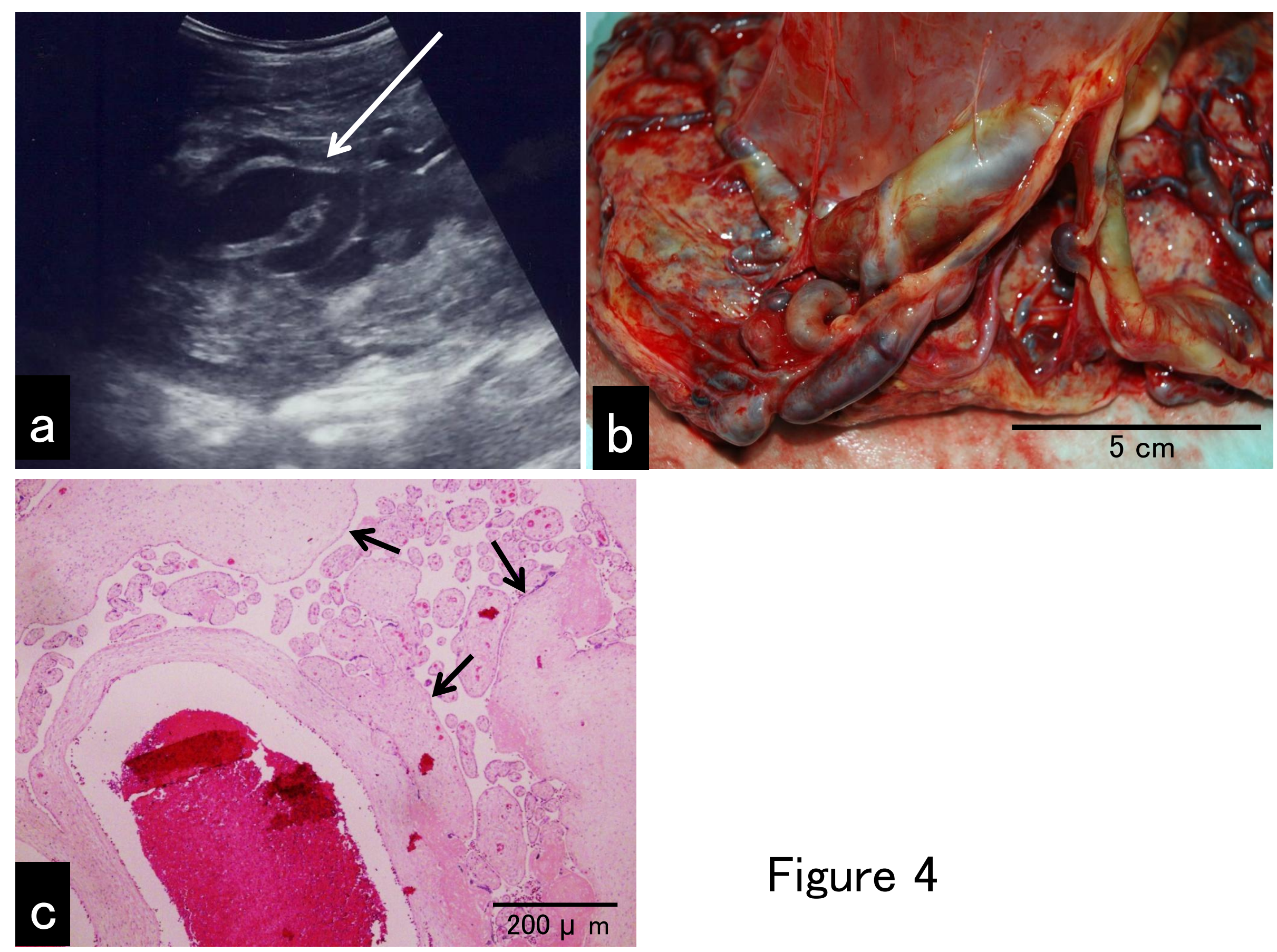

Figure 4 


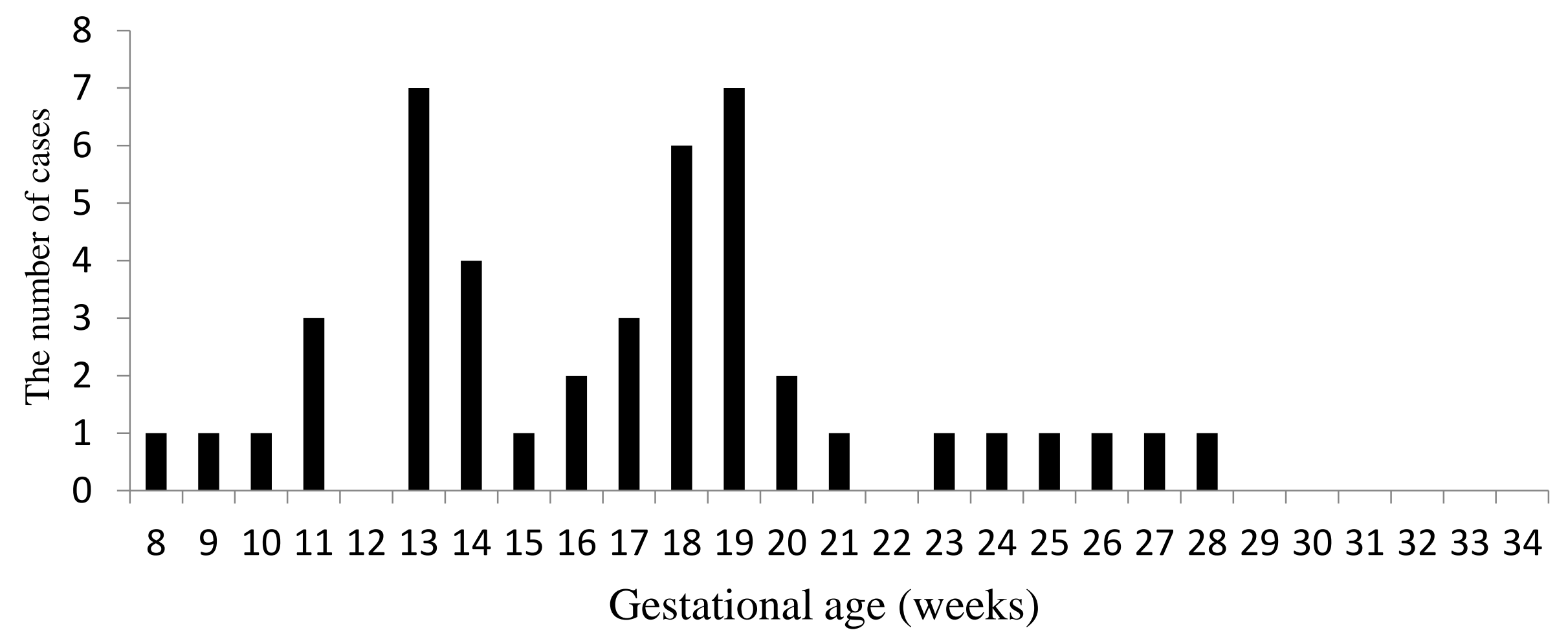

Figure 5 


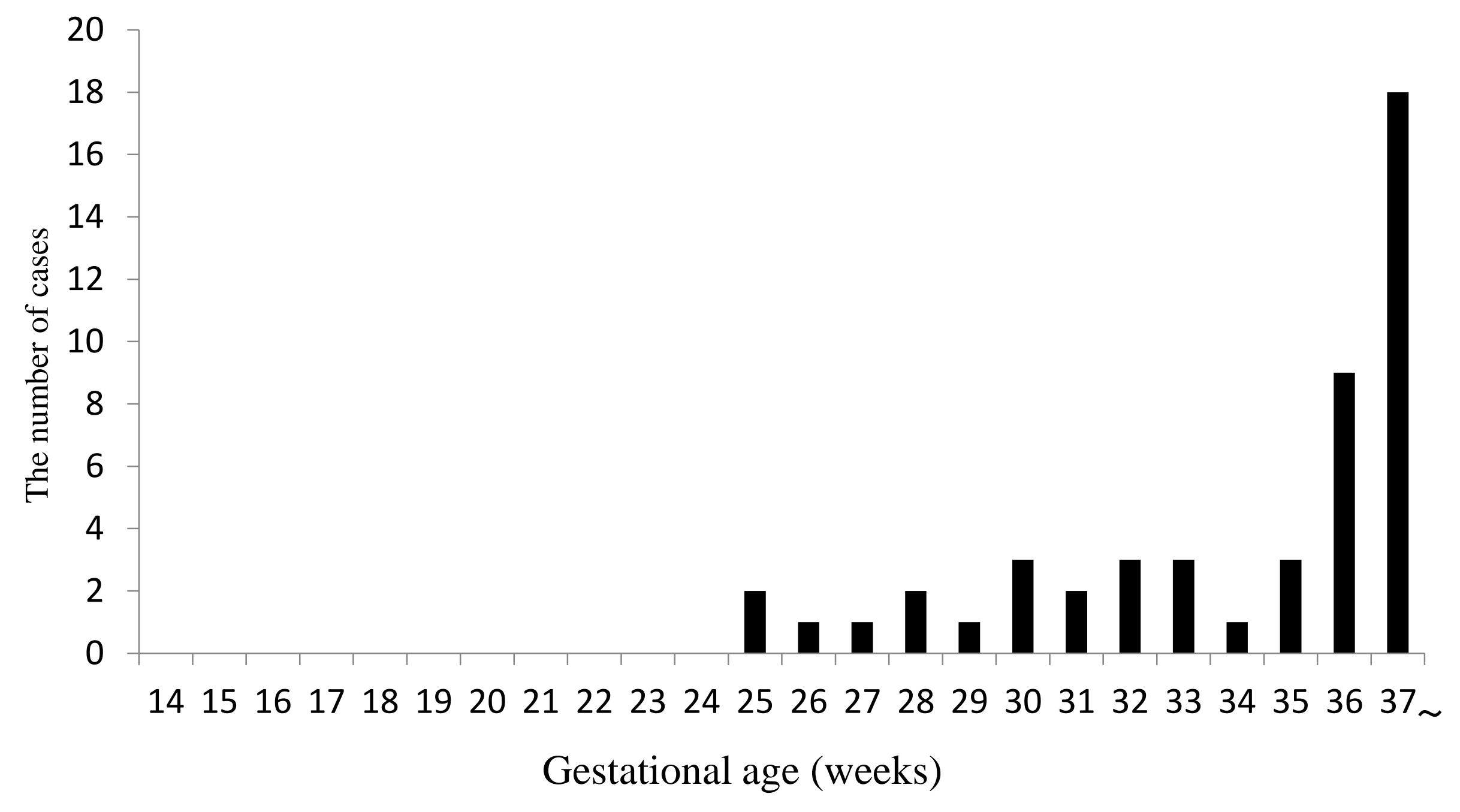

Figure 6 